\title{
DEVELOPMENT OF A CONTROL STRATEGY FOR MONITORING THE DELAMINATING DAMAGE IN DRILLING OF CARBON COMPOSITE LAMINATES
}

\author{
${ }^{1}$ P. Y. Andoh, ${ }^{2}$ F. Davis, ${ }^{2}$ S. Owusu-Ofori \\ ${ }^{1}$ Department of Mechanical Engineering, KNUST, Kumasi, Ghana \\ ${ }^{2}$ Department of Mechanical Engineering, North Carolina Agricultural and Technical State \\ University, Greensboro, NC 27411. \\ e-mail-andohp_2@yahoo.com
}

\begin{abstract}
Composite materials have attractive features, such as high strength to weight ratio and high stiffness to weight ratio. However, they are easily damaged during machining operations. A typical damage is delamination, which can occur when fiber reinforced composite laminates are drilled. Control of delamination is critical for the utilization of composite materials. This research seeks to develop a technique to control inter-ply delaminations during the drilling of laminated composites. A statistical factorial design technique is used to develop a model that relates the feed rate, cutting speed, and tool size to the acoustic parameters. A control algorithm is built from the model. The algorithm is used to modify the instantaneous feed rate in order to maintain the acoustic energy below a threshold value. This control strategy is effective in limiting the area of delamination. However, using high cutting speeds avoid the delamination of materials, but leads to high production costs due to excessive tool wear.
\end{abstract}

Keywords: Composite Laminates, Drilling, Damage, Acoustic Emission

\section{INTRODUCTION}

Carbon fiber reinforced composite materials are finding increased applications in many industries due to their excellent properties. Drilling of carbon fibre reinforced plastics (CFRP) composites is needed for joining of these composite structures. During drilling, delamination is an important factor, which affects the property of the drilled hole (Krishnamoorthy et al., 2009). The use of acoustic emission signals for "general-purpose" monitoring and control of machining processes is limited because the mechanism of generation of the acoustic emission signals is not completely understood and the analytical techniques for the acoustic emission signals are still in their infancy (Ravishankar and Murthy, 2000). Thus, utilization of acoustic emission in the drilling of composites poses challenges because of the material in-homogeneity and anisotropy (Arul et al., 2007). However, the acoustic emission generated during the drilling of composite laminates may contain valuable information on the state of the material being cut. It may provide realtime information on damage initiation and progression (Mizutani, 2000).

A study of the effects of cutting conditions on 


\section{Andoh et al.}

acoustic emission signals response have been conducted using statistical factorial design method. The significant effects were obtained for each acoustic emission parameter. It was found out that the energy response has the highest significant effects due to the cutting parameters. Hence a model can then be established to relate the acoustic emission energy response and the cutting parameters which can be used to monitor and control the area of delamination during the drilling process (Andoh et al., 2007) This research seeks to develop a technique to control inter-ply delaminations during the drilling of laminated composites with the use of acoustic emission signals. A specific objective of this research is to develop a mathematical model relating acoustic energy and cutting parameters that can be used to monitor changes in the delamination area during the drilling action.

\section{MATERIAL AND METHOD}

\section{Control Strategy}

Adaptive control schemes provide an opportunity to achieve improved control performance by basing the control action on a mathematical model of the process. This model includes the time delay that is used to forecast the process response and subsequently calculate the actual control action required to obtain a set point. The mathematical model is adjusted automatically to compensate for changes in the process characteristics so that a controller can maintain control under various operating conditions. Commercially produced controllers of this type are commonly termed "model-based" adaptive controllers. These schemes rely on the creation of an exact mathematical model of the process for each application of the controller. The controller uses mathematical models of the process to forecast the process response so that the $\mathrm{s}$ point is attained as rapidly as possible with little or no overshoot, and a minimal control effort. Figure 1 describes the basic algorithm steps used in the controller, where,

$$
\text { and } f_{n}=f_{\text {old }}-\Delta f \text { respectively }
$$

CONTROLLER

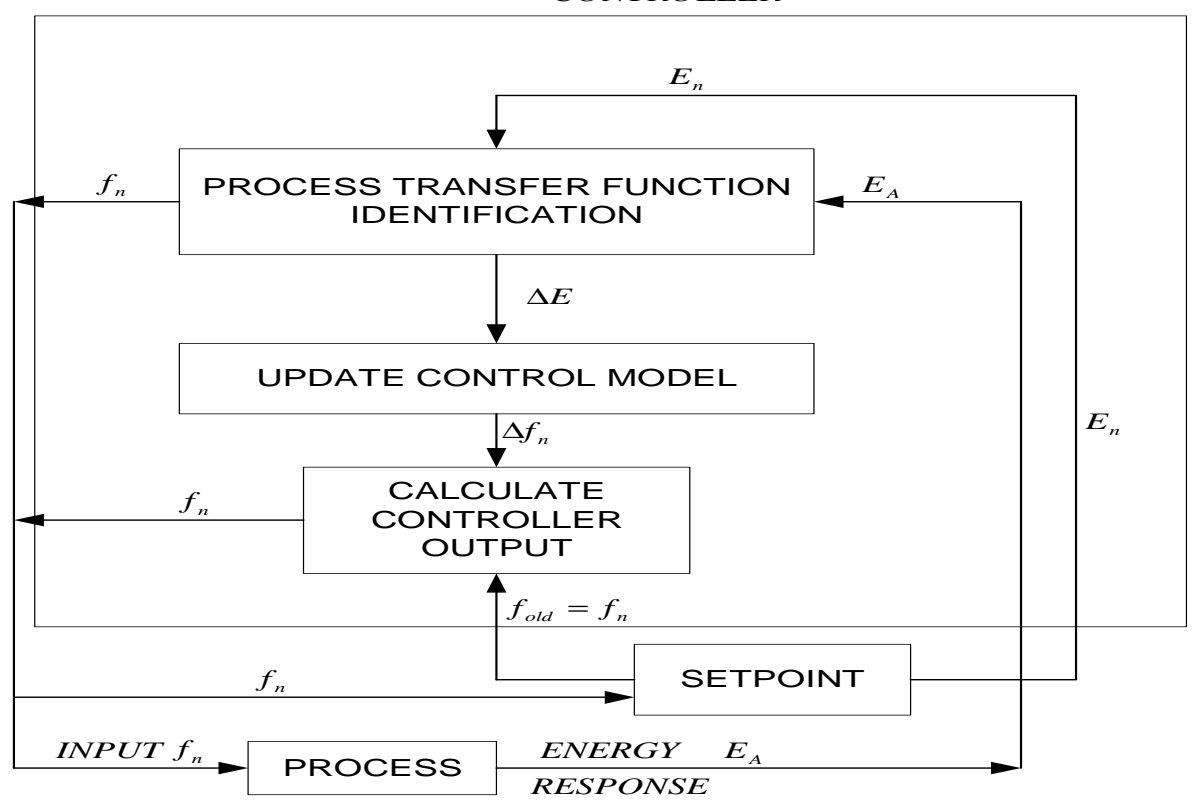

Figure 1: Basic Steps in Adaptive Control 
Development of a control strategy... 144

\section{Experimental Method}

The materials selected for the experiment were: (1) A $57 \mathrm{ply}, 9 \mathrm{~mm}$ (0.342 inch) thick carbon/ epoxy composite panel made of Amoco T300 $3 \mathrm{~K}$ Uni-Carbon in warp with S-glass in the fill direction. This material is referred to as "Amoco T300" in the rest of the work. (2) A 26 ply, $9 \mathrm{~mm}$ (0.342 inch) thick carbon/epoxy composite panel made of Hercules AS4 high strength, high modulus graphite fiber and a Hercules 3501 amine-cured epoxy resin matrix. This material is referred to as "Hercules AS4" in the rest of the work._Acoustic Emission (AE) signals were collected during each drilling operation. The schematic diagram of the experimental set-up for the measurement of the $\mathrm{AE}$ signal and the drilling process is shown in Figure 2.

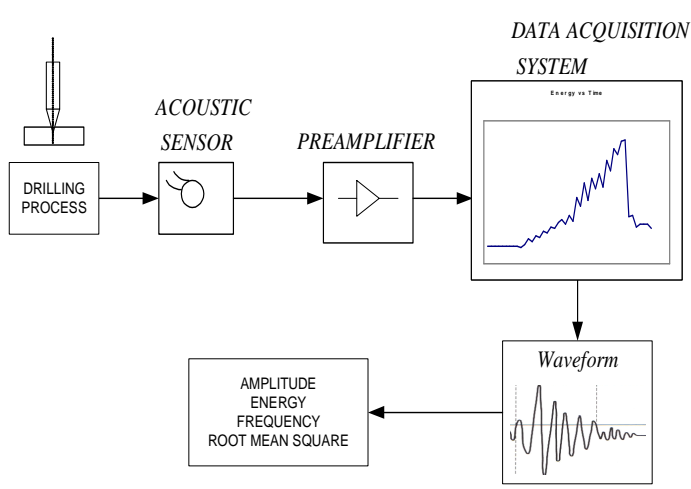

Figure 2: Schematic Showing Experimental Set-Up

The threshold frequency for the acoustic signal was set at $35 \mathrm{MHz}$ with one channel and a sample rate of $4 \mathrm{MHz}$, which is greater than ten times the natural frequency of the sensor used. This frequency was kept a good deal above the Nyquist range to avoid the aliasing problem. $\mathrm{AE}$ signal measurement parameters versus time plots were obtained for each drill test and the corresponding data were collected for subsequent analysis.

Development of Mathematical Model for the Process Transfer Function

Factorial designs are of importance for a number of reasons: 1) They require relatively few runs per factor studied; 2) They can indicate major trends that determine promising directions for further experimentation. Three quantitative variables, namely, feed rate $\left(\mathrm{f}-\mathrm{mms}^{-1}\right)$, cutting speed ( $\mathrm{v}-\mathrm{mm} / \mathrm{min})$, and drill diameter $(\mathrm{d}$ $-\mathrm{mm}$ ) are used to study the response of the AE signals. The Energy (E) is monitored. Table 1 presents the levels of the variable used in this work. The cutting speed and the feed rate are selected to correspond to the typical range of values used in the drilling of composite laminates. The experiment is performed at each combination of the feed rate, cutting speed and tool diameter. Thus, there are $2^{3}=8$ experimental conditions.

Table 1: The Experimental Matrix

\begin{tabular}{lll}
\hline Variables & $\begin{array}{l}\text { Lower } \\
\text { Level }(-)\end{array}$ & $\begin{array}{l}\text { Upper Level } \\
(+)\end{array}$ \\
\hline $\begin{array}{l}\text { Feed Rate f (mm/ } \\
\text { sec) }\end{array}$ & 2 & 8 \\
$\begin{array}{l}\text { Cutting Speed v } \\
(\mathrm{mm} / \mathrm{min})\end{array}$ & 1000 & 2500 \\
$\begin{array}{l}\text { Tool Diameter d } \\
(\mathrm{mm})\end{array}$ & 6.4 & 12.8 \\
\hline
\end{tabular}

For each setting, a hole is drilled and the acoustic signals are obtained. Each experiment is replicated at each point. The measurable quantities for the energy response are recorded. The averages of the two runs are computed for each set of conditions (Andoh, 2005). The computed averages are used as the responses for each condition in calculating the main effects and the interaction effects for each $\mathrm{AE}$ response. The major goal of these experiments is to generate a model that may be used to develop a control algorithm.

The main effect of each of the process variables reflect the changes of the respective responses as the process variables change from a low to a high level. The average of the four measures is the main effect of the factor (variable) and is given as: 


\section{Andoh et al.}

The main effect of the feed rate is

$E_{f}=\frac{1}{4}\left\{\left(E_{2}+E_{4}+E_{6}+E_{8}\right)-\left(E_{1}+E_{3}+E_{5}+E_{7}\right)\right\}(1)$

The main effect of the cutting speed is

$E_{v}=\frac{1}{4}\left\{\left(E_{3}+E_{4}+E_{7}+E_{8}\right)-\left(E_{1}+E_{2}+E_{5}+E_{6}\right)\right\}$

The main effect of the drill size is

$E_{d}=\frac{1}{4}\left\{\left(E_{5}+E_{6}+E_{7}+E_{8}\right)-\left(E_{1}+E_{2}+E_{3}+E_{4}\right)\right\}$

Two or more of the variables may jointly influence the responses. These joint influences are referred to as interactions. These interactions are given as follows:

The interaction between the feed rate and the cutting speed is defined as:

$I_{f v}=\frac{1}{4}\left\{\left(E_{1}+E_{4}+E_{5}+E_{8}\right)-\left(E_{2}+E_{3}+E_{6}+E_{7}\right)\right\}$

The interaction between the feed rate and the drill diameter is defined as:

$$
I_{f d}=\frac{1}{4}\left\{\left(E_{1}+E_{3}+E_{6}+E_{8}\right)-\left(E_{2}+E_{5}+E_{5}+E_{7}\right)\right\}
$$

The interaction between the cutting speed and the drill diameter is defined as:

$I_{v d}=\frac{1}{4}\left\{\left(E_{1}+E_{2}+E_{7}+E_{8}\right)-\left(E_{3}+E_{4}+E_{5}+E_{6}\right)\right\}$

The three-factor interaction is expressed as

$I_{\text {fvd }}=\frac{1}{4}\left\{\left(E_{2}+E_{3}+E_{5}+E_{8}\right)-\left(E_{1}+E_{4}+E_{6}+E_{7}\right)\right\}$

The mean of the runs is defined as

$E_{M}=\left[\sum_{1}^{8} \frac{E_{i}}{8}\right]$

where $E_{i}$ is the acoustic energy parameters.

In general, if $\mathrm{g}$ sets of experimental conditions are genuinely replicated and the $n_{i}$ replicate runs made at the $\mathrm{i}^{\text {th }}$ set yield an $S_{i}^{2}$ estimate having $v_{i}=n_{i}-1$ degree(s) of freedom, the estimate of run variance is $s^{2}=\frac{v_{1} s_{1}^{2}+v_{2} s_{2}^{2}+v_{3} s_{3}^{2}+\ldots+v_{g} s_{g}^{2}}{v_{1}+v_{2}+v_{3}+\ldots+v_{g}}$

With only $n_{i}=2$ replicates at each of the g sets of conditions, with $v_{i}=1$, and $d_{i}$ is the difference between the duplicate observations for the ith set of conditions.

Thus $s_{i}^{2}=d_{i}^{2} / 2$

In general, if a total of $\mathrm{N}$ runs is made conducting a replicated factorial design, then the variance of an effect is given as:

$V($ effect $)=\frac{4}{N} s^{2}$. The standard error of the effect

is given as $s_{e}=\sqrt{V(\text { effect })}$ (Hunter, 1978).

A full model may consist of three main effects, three two-factor interaction and a three-factor interaction. This is defined as:

$E=\left[\begin{array}{l}\alpha_{0}+\alpha_{1} f+\alpha_{2} v+\alpha_{3} d+ \\ \alpha_{4} f v+\alpha_{5} f d+\alpha_{6} f v+\alpha_{7} f v d\end{array}\right]$

where $\alpha_{0}, \alpha_{1}, \ldots, \alpha_{7}$ are the constants and $\mathrm{f}, \mathrm{v}$, and $\mathrm{d}$ are the feed rate, cutting speed and drill diameter, respectively. It can be shown that

$$
\begin{aligned}
& \alpha_{0}=E_{M}, \alpha_{1}=\frac{E_{f}}{2}, \alpha_{2}=\frac{E_{v}}{2}, \\
& \alpha_{3}=\frac{E_{d}}{2}, \alpha_{4}=\frac{I_{f v}}{2}, \alpha_{5}=\frac{I_{f d}}{2}, \\
& \alpha_{6}=\frac{I_{v d}}{2} \quad \text { and } \quad \alpha_{7}=\frac{I_{f v d}}{2}
\end{aligned}
$$

It is assumed that the hole size is known, and the cutting speed is selected based on the recommendation in practice. The response may then be related only to the feed rate. Hence, the energy model in Equation 9 may be reduced to

$E_{n}=J_{0}+J_{1} f$

where $\mathbf{J}_{0}$ and $\mathbf{J}_{1}$ are functions of the cutting speed and the drill diameter. Let

$E_{n}=J_{0}+J_{1} f_{n}$ 
Using the back shift at any instant for one step backward, Equation 11 can be written as:

$E_{n-1}=J_{0}+J_{1} f_{n-1}$

Combining Equations 11 and 12, the discrete model can be written as:

$E_{n}=E_{n-1}+J_{1} f_{n}-J_{1} f_{n-1}$

Using the back shift operator in Equation 13, the transfer function for the process may also be written as

$(1-B) E_{n}=(1-B) J_{1} f_{n}$

Thus, $G_{P}(B)=\frac{E_{n}}{f_{n}}=J_{1}$

The transfer function is used to develop the control algorithm for the system.

\section{Determination of the Set Points}

The thickness of the material is divided into ten equal depths (stages) as shown in Figure 4. This division is due to the fact that delamination initiates at a certain ply number and increases as a tool advances into the material. By dividing the thickness of the material, one is able to determine the ply at which delamination initiates and its corresponding energy response. In addition, delamination parameters and the energy response may be determined at each step as the tool advances. A model was then developed to relate the change in energy response and the area of delamination. A feed rate of $1 \mathrm{~mm} / \mathrm{sec}$, a cutting speed of $1600 \mathrm{~mm} /$ $\mathrm{sec}$ and a drill diameter of $6.4 \mathrm{~mm}$ are used to drill holes to different depths (stages). The acoustic energy responses are recorded and the corresponding longitudinal and transverse crack lengths are measured at each stage. The area of delamination is then computed from the two crack lengths. This is repeated for four other feed rates $(2,3,4$ and $5 \mathrm{~mm} / \mathrm{s})$. The energy responses and the delamination parameters were then obtained for the two materials.

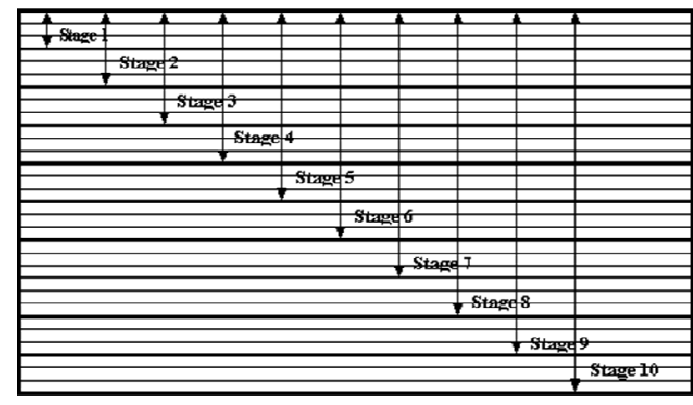

Figure 4: Illustration of drill stages and ply numbers

Let $E_{n}$ be the energy response obtained at time $t$ and $E_{0}$ the energy obtained when there is no delamination. The change in energy response $\Delta \mathrm{E}_{\mathrm{n}}$ is given as:

$\Delta E_{n}=E_{n}-E_{0}$

Using the values obtained for both the area of delamination and the energy response, plots are generated for the five feed rates. A model can then be generated to relate the energy and the delamination area which may be expressed as:

$\Delta E_{n}=a_{0}+a_{1} A_{d}$

where $\mathrm{a}_{0}$ (intercept) and $\mathrm{a}_{1}$ (slope) are constants and are functions of the feed rate and the characteristics of the material. The constants $\mathrm{a}_{0}$ and $a_{1}$ need to be studied in regard to the cutting parameters and the characteristics of the material.

The values of the constants are extracted from plots of change in acoustic energy response and the area of delamination for the two materials. These results were also plotted to relate the feed rate and the model constants.

\section{Demonstration of the Control Strategy}

Sets of experiments are performed to establish the effectiveness of the control strategy. First, the thickness of the material is divided into five sections as shown in Figure 5. The control action is implemented at each section. 


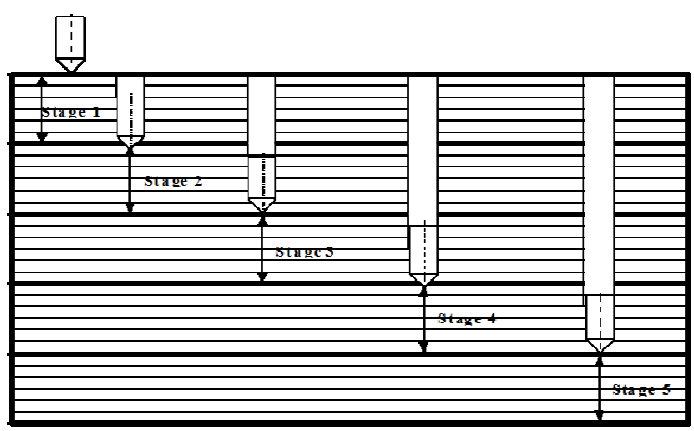

Figure 5: Illustration of the Stages of Control Action

The algorithm is implemented at each depth in the material to determine the status of the process and to modify the feed rate if the energy level exceeds the threshold (set) value $E_{n}$. Each part is drilled at a cutting speed of $1000 \mathrm{~mm} /$ min and a drill diameter of $6.4 \mathrm{~mm}(1 / 4 \mathrm{inch})$. The operations are performed using the proposed control strategy. The experimental set-up and the $\mathrm{AE}$ sensor system are as provided in previous section. Figure 6 shows the steps used to compute the initial conditions and to monitor the feed rate in order to maintain the recorded energy response below the threshold (reference) value. The initial feed rate is computed for each material based on the control algorithm presented in Figure 6.

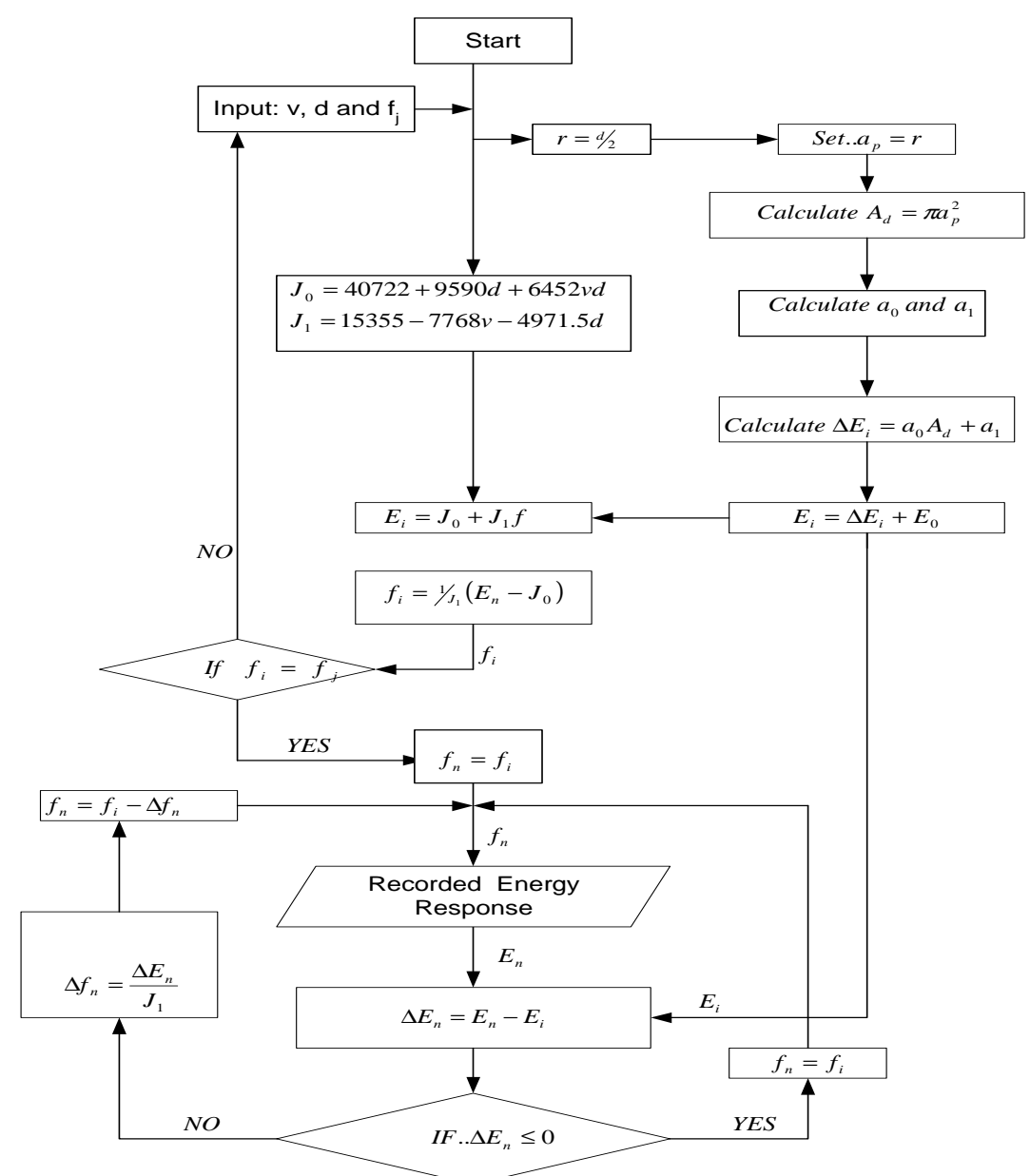

Figure 6: Implementation of the Control Algorithm 
Development of a control strategy... 148

Hence, a feed rate of $3.5 \mathrm{~mm} / \mathrm{sec}$, a cutting speed of $1000 \mathrm{~mm} / \mathrm{min}$ and a drill diameter of $6.4 \mathrm{~mm}(1 / 4 \mathrm{inch})$ are used for the Amoco T300 as the initial cutting conditions. This procedure is repeated for the Hercules AS4 and the results are presented in Table 2. These initial cutting conditions are programmed into the Computer Numerically Controlled (CNC) machine programme as inputs for the two materials. The process is then monitored via the acoustic signals as the tool advances into the material.

Table 2: Selection of the Initial Cutting Conditions

\begin{tabular}{llll}
\hline PARAMETERS & $\begin{array}{l}\text { Amoco } \\
\text { T300 }\end{array}$ & $\begin{array}{l}\text { Hercules } \\
\text { AS4 }\end{array}$ \\
\hline $\begin{array}{l}\text { Cutting Speed } \\
(\mathrm{mm} / \mathrm{min})\end{array}$ & v & 1000.00 & 1000.00 \\
$\begin{array}{l}\text { Drill Size }(\mathrm{mm}) \\
\text { Feed Rate }(\mathrm{mm} / \mathrm{s})\end{array}$ & d & 6.40 & 6.40 \\
\hline
\end{tabular}

During each stage of the drilling process, the AE energy responses are monitored and the peak values are compared to the reference energy response. If the measured energy response is greater than the reference energy response, then a new feed rate must be computed for the next stage (Figure 7). From Figure 6 , if $\Delta \mathrm{E}_{\mathrm{n}}$ is less than zero, then the feed rate is not changed. However, if $\Delta \mathrm{E}_{\mathrm{n}}$ is greater than zero, then the feed rate is modified to the new value

$f=f_{n}-\frac{\Delta E_{n}}{J_{1}}$.

This procedure is repeated for the rest of the stages as the drill travels through the part. The energy responses are recorded for both the controlled and the uncontrolled experiments.

\section{RESULTS AND DISCUSSION \\ Process Model}

Using equations 1 through 9 and the results obtained for the AE responses during the drilling process, the $d_{i}$ and the $d_{i}^{2} / 2$ are computed for each $i^{\text {th }}$ condition. These values are used to compute the corresponding standard errors for the Acoustic Energy response. The results are as presented in Table 3.

These results are used to establish the models of the Acoustic Energy response and the cutting conditions. By examining the confidence intervals of each result, it can be determined that all the effects and interactions are significant. Hence all the effects and interactions were used to develop the empirical model for the energy response with the use of Equation 13 for both materials. Thus, the model for the energy response for both the Amoco T300 and Hercules AS4 are

$E=40722+15355 f+1239 v+9590 d-$ $7768 f v+6453 v d-4972 f d+1093$ fvd

and

$E=41744+16074 f+1024 v+9760 d-6595 f v$ $+6645 v d-4169 f d+1256 f v d$

Since the process parameters (f, v, and d) are coded, their values are -1 to +1 in these models. These models were then verified and found out to be within experimental error. These models can be used to develop a control algorithm to monitor, forecast, and control the area of delamination during the drilling process. For instance if a cutting feed of $1000 \mathrm{mms}^{-1}$ and a drill of $6.4 \mathrm{~mm}$ are used, the process models are given as: $E_{n}=36345.5+29187.5 f$ and $E_{n}=$ $37584+28094 f$ for Amoco T300 and Hercules AS4 respectively.

\section{Set Point Model}

Figures 7 shows the graph of change in acoustic energy response and the area of delamination for the two materials (that is Hercules AS4 and Amoco T300) using five different feed rates and Figure 8 shows the graph of the model constants and the feed rates. Both plots show a linear relationship of the model constants $\left(a_{0}\right.$ and $\mathrm{a}_{1}$ ) with the feed rate. The models obtained may be used to develop an algorithm to control the delamination area during drilling operations. The results obtained for the set point model from Figures 7 and 8 are presented in Table 4. 
149 Andoh et al.

Table 3: Summary of the Factorial Experimental Results

\begin{tabular}{ccccc}
\hline \multirow{2}{*}{ EFFECTS } & \multicolumn{2}{c}{ AMOCO T300 } & \multicolumn{2}{c}{ HERCULES AS4 } \\
& Results & Remarks & Results & Remarks \\
\hline $\mathrm{E}_{\mathrm{M}}$ & $40722 \pm 1516.33$ & & $41744 \pm 1525.98$ & \\
$\mathrm{E}_{\mathrm{f}}$ & $30711 \pm 1516.33$ & Significant & $32148 \pm 1525.98$ & Significant \\
$\mathrm{E}_{\mathrm{v}}$ & $2477.25 \pm 1516.33$ & Significant & $2048 \pm 1525.98$ & Significant \\
$\mathrm{E}_{\mathrm{d}}$ & $19180 \pm 1516.33$ & Significant & $19520 \pm 1525.98$ & Significant \\
$\mathrm{I}_{\mathrm{fv}}$ & $-15536 \pm 1516.33$ & Significant & $-13190 \pm 1525.98$ & Significant \\
$\mathrm{I}_{\mathrm{fd}}$ & $-9943 \pm 1516.33$ & Significant & $-13290 \pm 1525.98$ & Significant \\
$\mathrm{I}_{\mathrm{vd}}$ & $12905 \pm 1516.33$ & Significant & $8338 \pm 1525.98$ & Significant \\
$\mathrm{I}_{\mathrm{fvd}}$ & $2186 \pm 1516.33$ & Significant & $2512 \pm 1525.98$ & Significant \\
\hline
\end{tabular}

Table 4: The parameters for the Set Point Model

\begin{tabular}{llll}
\hline PARAMETERS & & Amoco T300 & Hercules AS4 \\
\hline Intercept & $\mathrm{a}_{0}$ & 1203.10 & 1531.30 \\
Slope & $\mathrm{a}_{1}$ & 13.68 & 20.35 \\
Change in Energy Response & $\Delta \mathrm{E}$ & 1520.74 & 2003.81 \\
En. R without Delamination & $\mathrm{E}_{0}$ & 19961.26 & 19230.19 \\
Reference Energy Response & $\mathrm{E}$ & 21482.00 & 21234.00 \\
\hline
\end{tabular}

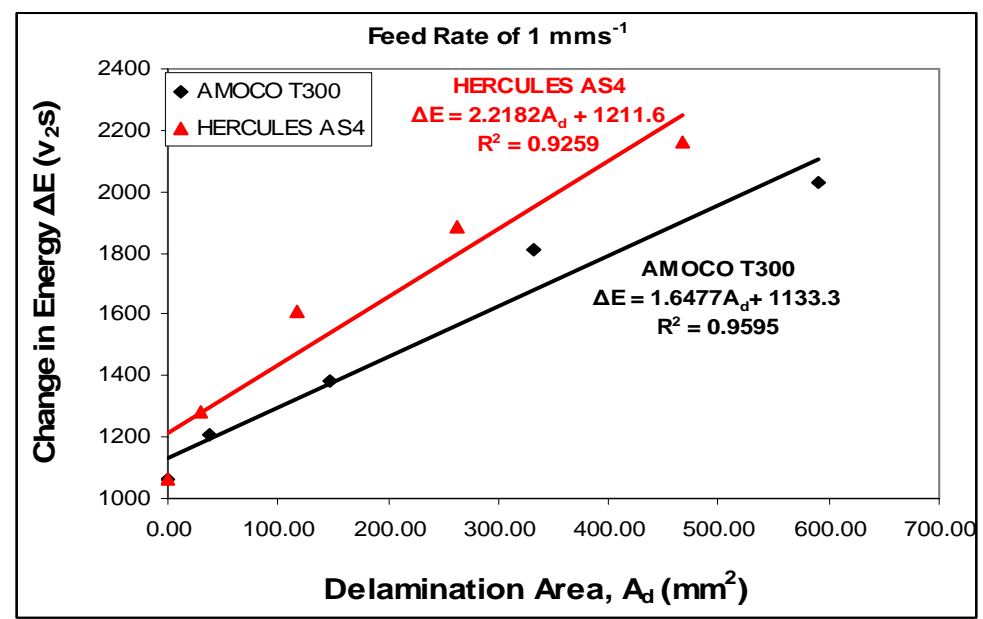

Figure 7a: Graph of change in acoustic energy and area of delamination for feed rate of $1 \mathrm{mms}^{-1}$ 


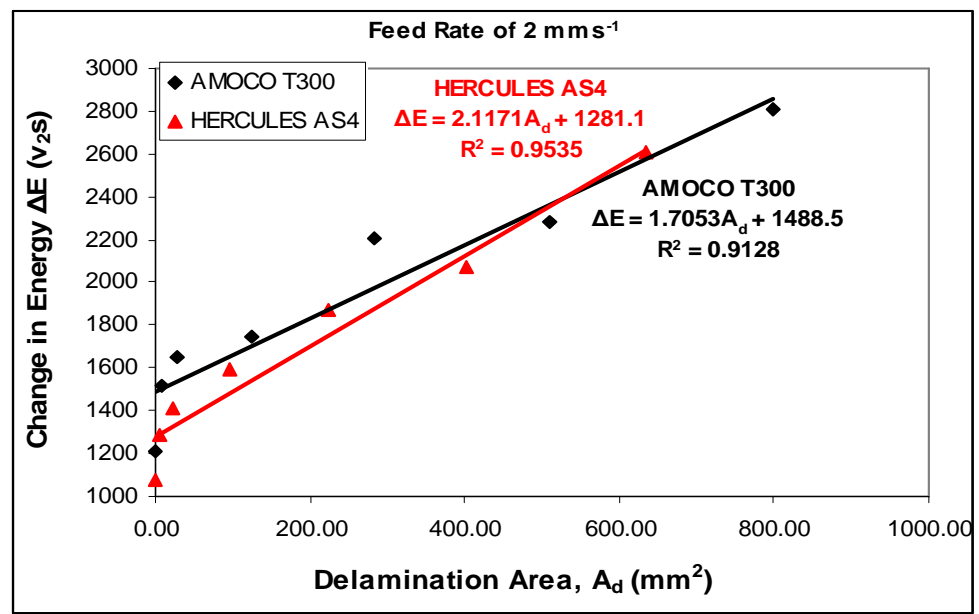

Figure 7b: Graph of change in acoustic energy and area of delamination for feed rate of $2 \mathrm{mms}^{-1}$

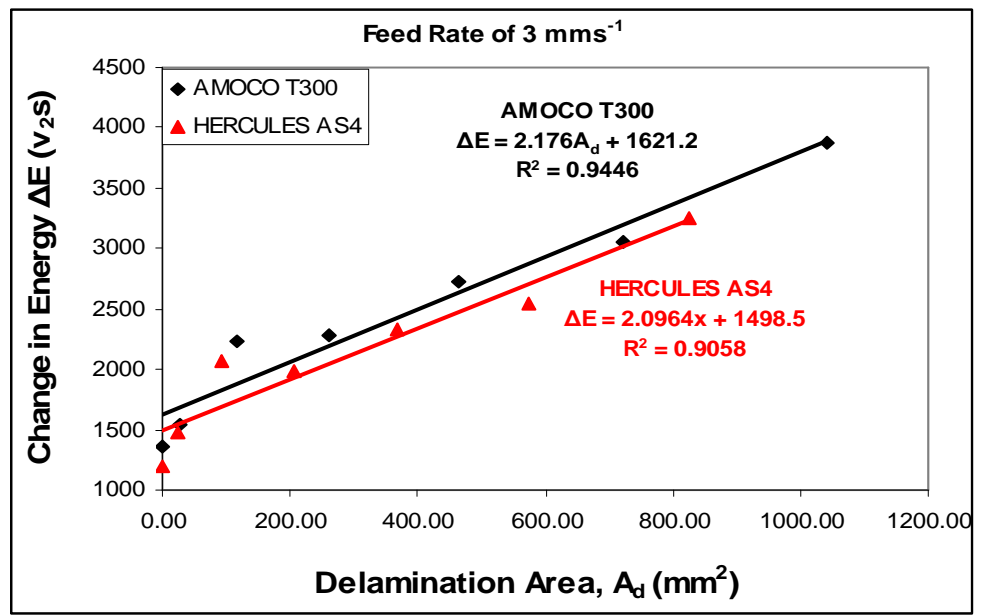

Figure 7c: Graph of change in acoustic energy and area of delamination for feed rate of $3 \mathrm{mms}^{-1}$ 
151 Andoh et al.

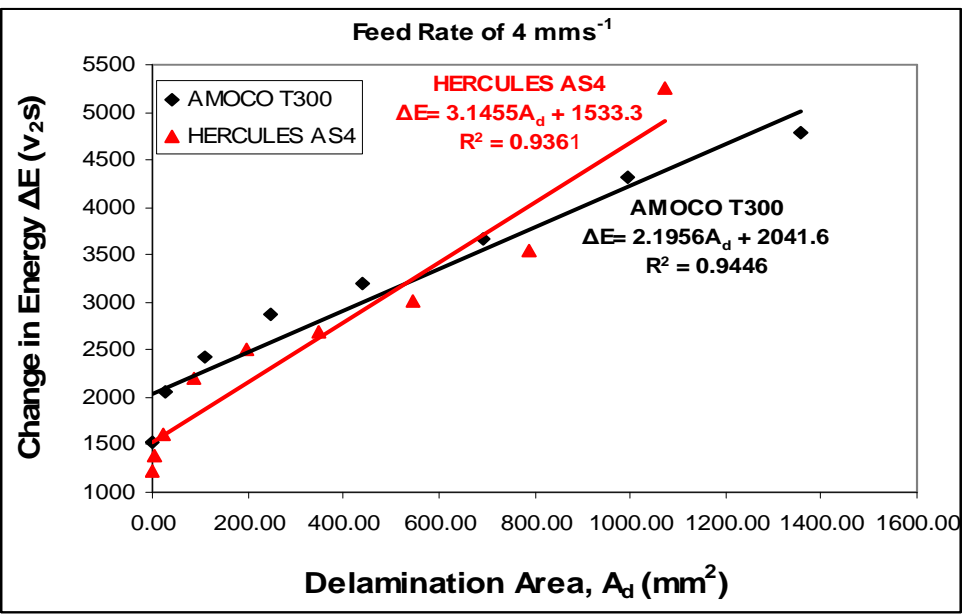

Figure 7d: Graph of change in acoustic energy and area of delamination for feed rate of $4 \mathrm{mms}^{-1}$

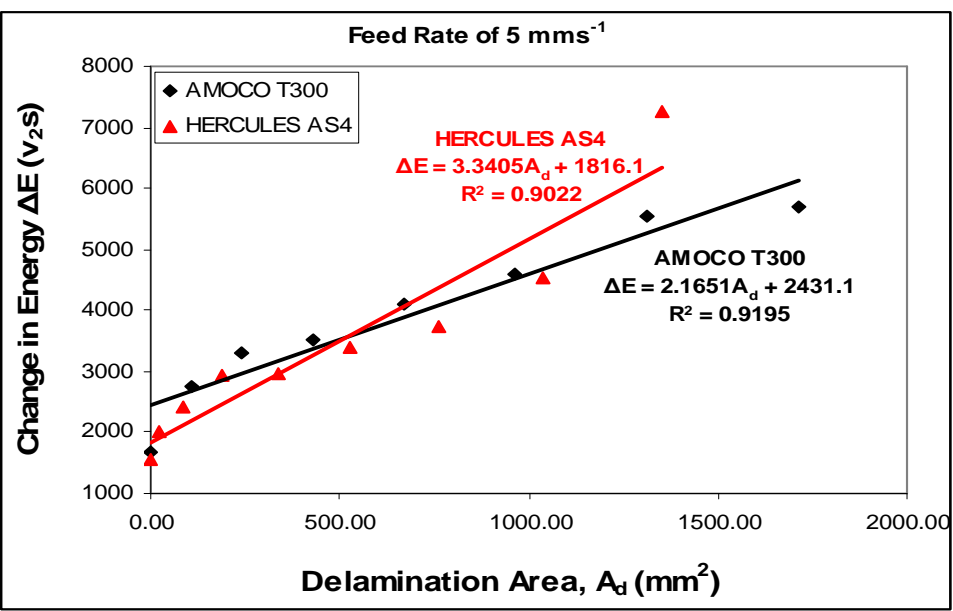

Figure 7e: Graph of change in acoustic energy and area of delamination for feed rate of $10 \mathrm{~mm} / \mathrm{s}$ 


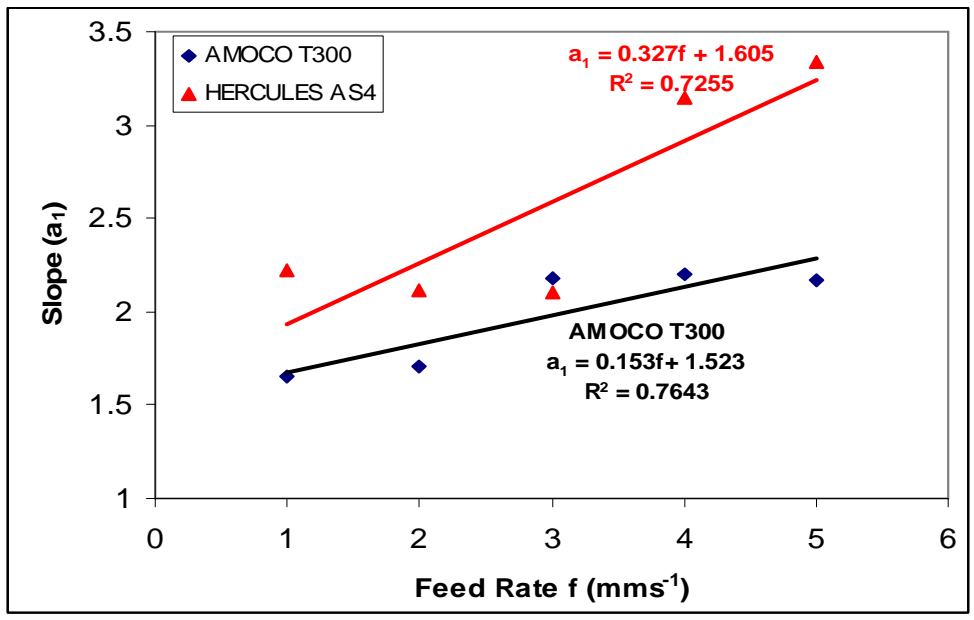

Figure 8a: Graph of slope $\left(a_{1}\right)$ Versus feed rate

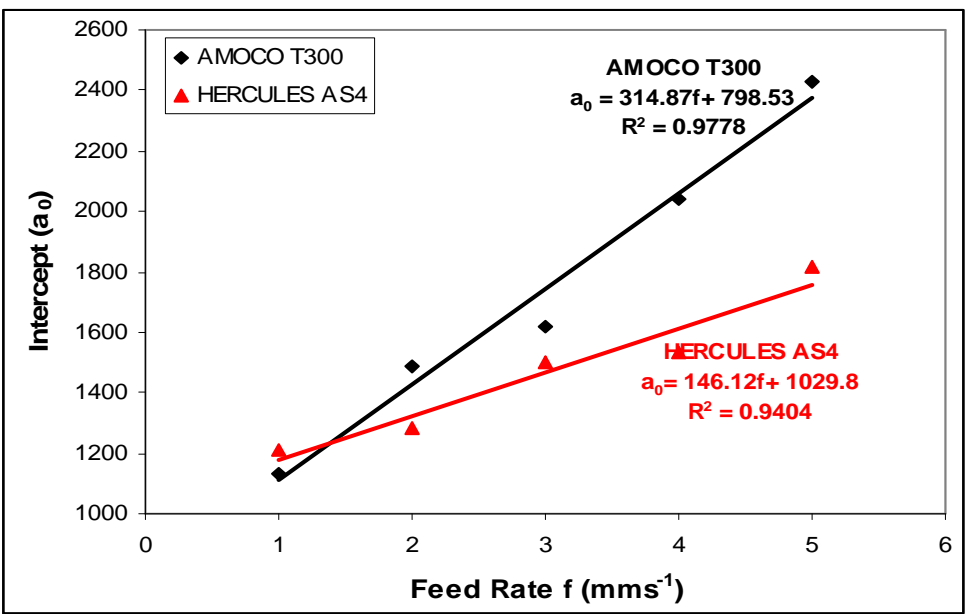

Figure 8b: Graph of intercept $\left(a_{0}\right)$ Versus feed rate 


\section{Andoh et al.}

The Controlled and Uncontrolled Process The results for the energy responses are then plotted against the ply number and are presented in Figure 9.

The uncontrolled signal remains above the threshold value during the entire process. For the controlled process, the energy at ply number 5 exceeds the threshold. The system changes the feed rate to bring this value to a value lower than the previous value but greater than the threshold. This process is repeated at ply numbers 10 and 20 . Thus, the developed control algorithm tends to reduce the energy level that has been determined to be related to the area of delamination.

The algorithm may then be used to control the area of delamination for different types of materials if parameters $\mathrm{a}_{0}$ and $\mathrm{a}_{1}$ are known. Thus, for any particular material used, " $\mathrm{a}_{0}$ and $\mathrm{a}_{1}$ " must be determined before the operator is able to select the reference energy value for the material. A second material (Hercules AS4) is used for comparison and the results are plotted and illustrated in Figure 10.

Since the control algorithm appears to be effective, six sets of experiments are per- formed using six different cutting speeds with a drill size of $6 \mathrm{~mm}$ in order to test the algorithm at cutting speeds other than the one used in the test phase. The method used in the previous example is also used to compute the initial feed rate during the drilling operation. Stereo microscope images are collected for the $5^{\text {th }}$ stage using the Hercules AS4 for each cutting speed. The results are presented in Table 5.

Table 5 indicates that as the cutting speed increases, the delamination area begins to decrease, irrespective of the feed rate. To illustrate this information, graphs of the energy responses versus the cutting speeds are plotted for each stage of the five-stage method. The plots for the $5^{\text {th }}$ stage are pre sented in Figures 11 and 12. This implies that there are no effects of cutting parameters on the area of delamination for cutting speeds of $1600 \mathrm{~mm} / \mathrm{min}$ and higher.

To select reference levels for control of drilling operations, one has to study the behavior of a material in terms of the area of delamination with respect to the $\mathrm{AE}$ energy response. A relationship must first be established between the area of delamination and the energy response so that " $\mathrm{a}_{0}$ and $\mathrm{a}_{1}$ " can

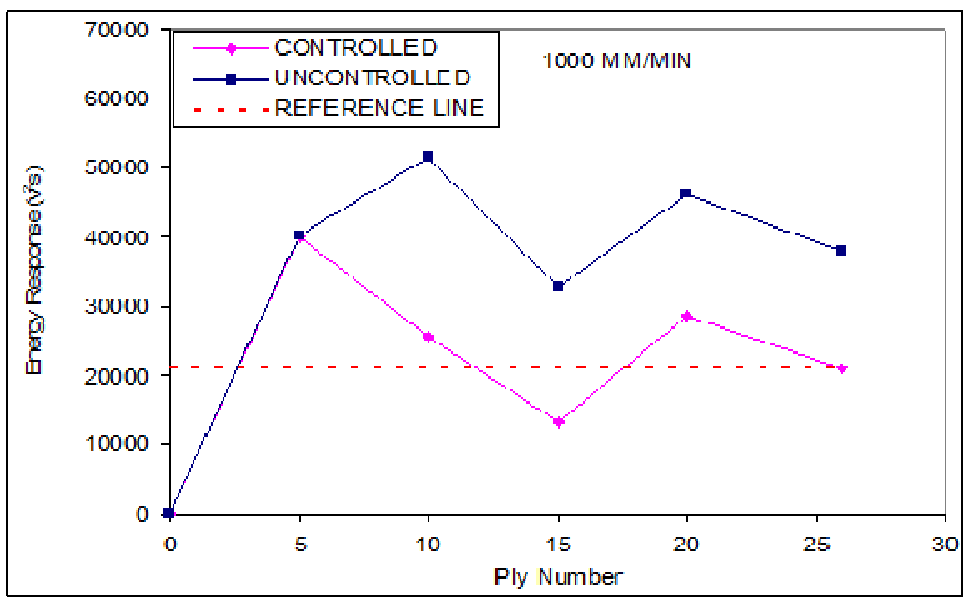

Figure 9: Graph of Energy Response versus Ply Number at Speed of $1000 \mathrm{~mm} / \mathrm{min}$ for Hercules AS4 


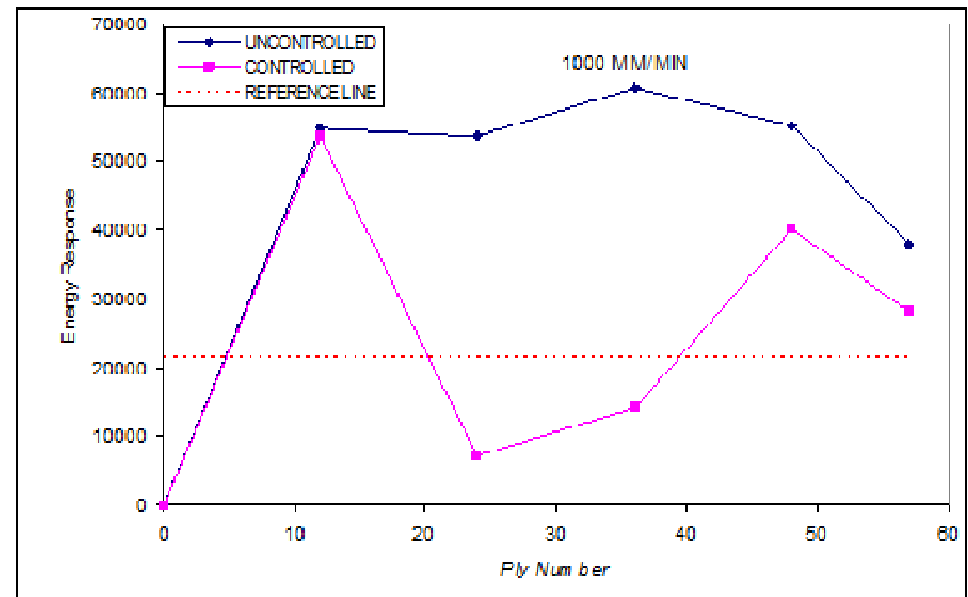

Figure 10: Graph of Energy Response versus Ply Number at Speed of $1000 \mathrm{~mm} / \mathrm{min}$ for Amoco T300

Table 5: Images obtained for the $5^{\mathrm{TH}}$ Stage of the Process using Hercules AS4

\begin{tabular}{|c|c|c|c|c|}
\hline \multirow[b]{2}{*}{$\begin{array}{l}\text { Cutting Speed } \\
(\mathbf{m m} / \mathbf{m i n})\end{array}$} & \multicolumn{2}{|c|}{ Uncontrolled } & \multicolumn{2}{|c|}{ Controlled } \\
\hline & Image & $\begin{array}{c}\text { Delamina- } \\
\text { tion Area } \\
\left(\mathbf{m m}^{2}\right)\end{array}$ & Image & $\begin{array}{c}\text { Delamination } \\
\text { Area }\left(\mathbf{m m}^{2}\right)\end{array}$ \\
\hline 1000 & & 1027.24 & (2) & 34.55 \\
\hline 1150 & & 577.45 & - & 15.45 \\
\hline 1300 & & 462.20 & $\theta$ & 8.67 \\
\hline 1450 & $-\infty$ & 206.25 & $\odot$ & 0.56 \\
\hline 1600 & $\rightarrow$ & 89.56 & $\odot$ & 0.25 \\
\hline
\end{tabular}

be known for a particular material. This relationship is due to the anisotropic nature of the composite material. Knowing the values of " $\mathrm{a}_{0}$ and $\mathrm{a}_{1}$ ", one can select the most appropriate model for a material and then implement the control algorithm to effect changes in the delamination area.

\section{CONCLUSION}

A control strategy is developed that uses a variable feed rate and instantaneous acoustic energy. A control algorithm is built from a model that uses the energy response. This construction is due to the fact that the energy response depends on all three cutting parameters, namely, 
155 Andoh et al.

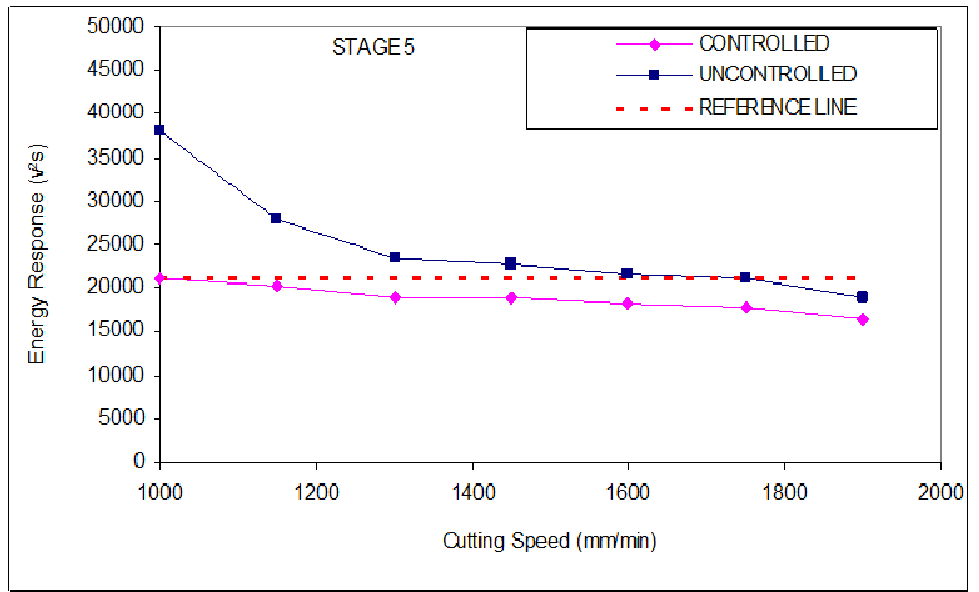

Figure 11: Energy Response versus Cutting Speed at Step 5 for Hercules AS4

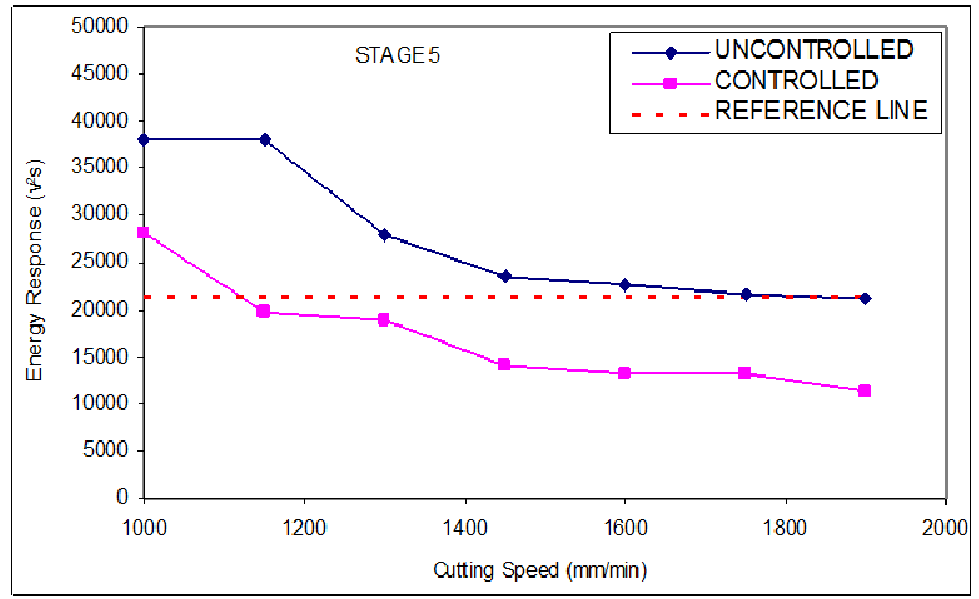

Figure 12: Energy Response versus Cutting Speed at Step 5 for Amoco T300

feed rate, cutting speed and tool diameter. The algorithm is used to re-define the appropriate instantaneous feed rate that maintains the acoustic energy within a predetermined range. The effectiveness of the control strategy is determined by implementing it with two different materials.

The control algorithm may be used to control the area of delamination for different types of materials if the material parameters are computed. For any particular material, the relationship between the change in the energy response and the area of delamination must be known in order to use the control algorithm.

The control methodology is most beneficial at low cutting speeds. The evidence suggests that 
high cutting speeds must be used to avoid the delamination of materials, if no control is used. However, the use of high cutting speeds may lead to high production costs due to excessive tool wear.

\section{REFERENCES}

Andoh, P. Y and Owusu Ofori, S. P. (2004). "A Quantitative Parameter for Non- D e structive Evaluation of Drilled Laminated Composite Parts", Transaction of North America Manufacturing Research Institution of SME, Charlotte, pp. 335-342.

Andoh, P. Y., Davis, F. and Antonio, J., (2007). "Effects of Cutting Parameters on Acoustic Emission Signal Response during Drilling of Laminated Composites using Factorial Design Method", JUST, 3 (2):98-106

Andoh, P. Y., (2005). "Monitoring and Control of Delamination in the Drilling of Carbon/Epoxy Composite Laminates", $\mathrm{PhD}$ Dissertation, North Carolina A \& $\mathrm{T}$ State University, Greensboro

Arul, S., Vijayaraghavan, L. and Malhotra, S. K., (2007). "Online monitoring of acoustic emission for quality control in drilling of polymeric composites", Journal of Materi als Processing Technology, 185 (1-3):184- 190

Hunter, W. G., Box, G. E. P. and Hunter, J. S., (1978). Statistic for Experimenters: An
Development of a control strategy... 156

introduction to Design, Data Analysis, and Model Building, Wiley, pp. 306-344.

Krishnamoorthy, A., Rajendra Boopathy, S. and Palanikumar, K. (2009). "Delamination during Drilling in Composite Laminates", Transactions of the ASME, Journal of Engineering for Industry, 112:236-239

Liu, J. J. and Dornfeld, D. A. (1996), "Modeling and analysis of acoustic emission in dia-mond turning Tool wear detection using time series analysis of acoustic emission", ASME Journal of manufacturing science and engineering, 118:199-207.

Mizutani, Y., N'agashima, K., Takemoto, M. and Ono K. (2000). "Fracture mechanism characterization of cross-ply carbon-fiber composites using acoustic emission analysis", NDT \&. E International, 33:101-10.

Ravishankar, SR. and Murthy CRL., (2000), "Characteristics of AE signals obtained during" drilling of composite laminates", NDT \& E International, 33:341-348.

Sackey, S. and Owusu Ofori, S. P., (2004), "A Dynamic Modeling Technique for Damage Progression in Drilling of Composite Laminates", Transaction of North America Manufacturing Research Institution of SME, Charlotte pp, 71-78. 